\title{
POLÍTICAS PÚBLICAS PARA O TURISMO SUSTENTÁVEL NO BRASIL - EVOLUCÃO E PERSPECTIVAS DE CRESCIMENTO PARA O SETOR
}

\author{
PUBLIC POLICIES FOR SUSTAINABLE TOURISM IN BRAZIL - EVOLUTION AND GROWTH \\ FORECASTS FOR THE SECTOR \\ POLÍTICAS PÚBLICAS PARA EL TURISMO SOSTENIBLE EN BRASIL - EVOLUCIÓN Y PERSPECTIVAS \\ DE CRECIMIENTO PARA EL SECTOR
}

Murilo de Alencar Souza Oliveira

Professor - Fac. Internacional Signorelli/FISIG; Analista em Gestão - FIOCRUZ

murilodealencar@bol.com.br

Doutor em Administração e Turismo/UNIVALI

Mestre em Gestão e Estratégia em Negócios/UFRuralRJ

Especialista em Desenvolvimento Integrado de Recursos Humanos/UFRJ

Bacharel em Administração/UERJ

Adriana Marques Rossetto

Professor Adjunto - Programa de Pós-Graduação em Urbanismo, História e Arquitetura da Cidade (PGAU-Cidades)- Depto. de Arquitetura e Urbanismo/UFSC

amarquesrossetto@gmail.com

Doutora em Engenharia de Produção/UFSC

Mestre em Engenharia Civil/UFSC

Bacharel em Arquitetura e Urbanismo/UFP

Data de Submissão: $27 / 05 / 2012$

Data de Aprovação: 11/09/2013

RESUMO

Este artigo teve como objetivo avaliar a evolução e o desenvolvimento das atividades do turismo no Brasil mediante apresentação de um panorama das políticas de gestão pública do setor, bem como dos programas voltados para um turismo sustentável. Constitui-se em um estudo teórico-descritivo, com abordagem qualitativa e utilização de pesquisa bibliográfica e documental. Efetuou-se reflexão sobre a condução e os resultados dos Planos Nacionais do Turismo (PNT) e dos Programas de Certificação em Turismo Sustentável (PCTS), Bem Receber, Turismo 100\%, e Bem Receber Copa. Concluiu-se que o turismo tem evoluído no país, porém numa intensidade menor que o crescimento mundial do setor, desperdiçando seu potencial de expansão e de benefícios passíveis de serem obtido, e com pouco direcionamento para a questão da sustentabilidade. Observa-se que existem normas de certificação em sustentabilidade do turismo, porém os programas governamentais de estímulo à adoção de práticas sustentáveis são isolados, de curto prazo e focados na operacionalização dos PNT e não como instrumentos estratégicos de gestão. Por isso não conseguem ter perenidade, nem obter consistência e credibilidade perante os diversos interessados na cadeia produtiva do turismo.

PALAVRAS-ChAVE: Políticas Públicas de Turismo. Turismo Sustentável. Certificação em Turismo Sustentável.

This paper evaluates the evolution and development of tourism activities in Brazil, through the presentation of an overview of policies for managing the public sector, as well as programs for sustainable tourism. 
It constitutes a theoretical-descriptive study with a qualitative approach, which uses bibliographic and documentary research. It reflects on the progress and results of the Planos Nacionais do Turismo (PNT) [National Tourism Plans] and the Programa de Certificação em Turismo Sustentável (PCTS) [Sustainable Tourism Certification Programs] Bem Receber, Turismo 100\%, and Bem Receber Copa. It is concluded that tourism has evolved in the country, but with a lower intensity than the global growth of the sector, wasting its potential for expansion and benefits that can be obtained, and with a lack of guidance on the issue of sustainability. It is observed that certification standards in sustainable tourism do exist, but government programs to encourage the adoption of sustainable practices are few, and those that do exist are short-term and are focused on the operationalization of PNT rather than acting as tools for strategic management. As a result, they cannot have continuity or achieve consistency and credibility with the various stakeholders in the tourism production chain.

KEYWORDS: Public Policies for Tourism. Sustainable Tourism. Sustainable Tourism Certification.

\section{RESUMEN}

Este artículo tuvo como objetivo evaluar la evolución y el desarrollo de las actividades del turismo en Brasil mediante la presentación de un panorama de las políticas de gestión pública del sector, así como de los programas dirigidos a un turismo sostenible. Constituye un estudio teórico descriptivo, con enfoque cualitativo y utilización de investigación bibliográfica y documental. Se efectuó una reflexión sobre la conducción y los resultados de los Planes Nacionales de Turismo (PNT) y de los Programas de Certificación en Turismo Sostenible (PCTS), Bien Recibir, Turismo 100\%, y Bien Recibir Copa. Se concluyó que el turismo ha evolucionado en el país, aunque con una intensidad menor al crecimiento mundial del sector, desperdiciando su potencial de expansión y de beneficios que podrían ser obtenidos, y con poco encaminamiento hacia la cuestión de la sostenibilidad. Se observa que existen normas de certificación en sostenibilidad del turismo, pero los programas gubernamentales de estímulo a la adopción de prácticas sostenibles son aislados, de corto plazo y están centrados en la operacionalización de los PNT y no como instrumentos estratégicos de gestión. Por ello no logran tener perennidad ni obtener consistencia y credibilidad ante los diversos interesados en la cadena productiva del turismo.

PALABRAS ClAVE: Políticas Públicas de Turismo. Turismo Sostenible. Certificación en Turismo Sostenible.

\section{INTRODUÇÃO}

O turismo consiste nas atividades realizadas pelos indivíduos durante viagens e estadas em lugares diferentes do habitual, por tempo inferior a um ano, seja a lazer ou a negócios (ORGANIZAÇÃO MUNDIAL DO TURISMO [OMT], 2001). Também é um fenômeno econômico-social contemporâneo que requer crescente consciência e interesse por estudos sobre seus impactos na sociedade em geral e em outros setores e atividades. Estudos que sejam adequados à realidade e ao momento histórico-social em que este fenômeno se manifesta (valores, ideologias e concepções de mundo) (DENCKER, 1998).

A atividade do turismo atravessa uma fase de expansão mundial desde a metade do século XX, com a explosão do 'turismo de massa' e a junção dos incrementos tecnológicos e de transportes advindos da Revolução Industrial, com a curiosidade e o desejo humano de experimentar novas sensações, descobertas e lazer (BOULLÓN, 1995). Seu crescimento no mundo revela uma capacidade de gerar benefícios econômicos (divisas, renda, empregos e impostos), socioculturais (qualificação profissional e educacional) e políticos (projeção de imagem e desenvolvimento) (PROGRAMA DAS NAÇÕES UNIDAS PARA O MEIO AMBIENTE [PNUMA]; OMT, 2005). Também, em alguns casos, gera outros ligados à conservação natural (criação de parques e reservas), cultural (proteção de 
monumentos e sítios históricos) e à melhoria da qualidade ambiental com o estabelecimento de padrões adequados de planejamento. Entretanto, nem sempre estes potenciais benefícios são observados nos destinos receptores, pois a lógica capitalista desconsidera importantes impactos em todos estes aspectos, como a modificação de usos e costumes locais; a estagnação ou a eliminação de atividades tradicionais (pesca, extração, etc.); dependência econômica; degradação da natureza e da desconsideração da cultura de comunidades receptoras (BOULLÓN, 1995).

Em fins da década de 1980 surgiram questionamentos relativos a estes efeitos negativos que as atividades de turismo causam no modo de vida, nos comportamentos, nas tradições e nas estruturas sociais dos destinos turísticos, das populações receptoras e dos turistas (SILVEIRA, 2005). Efeitos gerados por uma exploração sob pouco controle e que denotam falta de cuidados, de práticas adequadas e de planejamento quanto às consequências futuras de um turismo insustentável (BENI, 2000).

É crescente a preocupação quanto à inter-relação entre turismo e meio ambiente, por ser esta incontestável e complexa, uma vez que os recursos naturais constituem matéria-prima do turismo. A incorporação de práticas de sustentabilidade deve gerar experiências de alta satisfação, que tornem os turistas mais atentos e conscientes quanto aos impactos ambientais, e que passem a exigir o planejamento e a realização de um turismo sustentável e em constante melhoria quanto ao uso dos recursos naturais (PNUMA; OMT, 2005) nos países industrializados e naqueles em vias de desenvolvimento. Entretanto, esta realidade não é observada nos países cujo desenvolvimento ainda não se está consolidado.

No Brasil este cenário apresenta-se em toda sua complexidade. Com o grande crescimento do setor, [o número de desembarque de turistas estrangeiros foi $1.923 \%$ maior em 2009 do que em 1970, segundo o Ministério do Turismo (2011)], baseado inicialmente pelos atrativos naturais do país, presenciou-se uma série de "desmonte" de destinos turísticos, com a exaustão dos recursos naturais; alteração da cultura das comunidades receptoras; ocupação desordenada dos territórios; sem que os benefícios econômicos permanecessem no local. Este crescimento do setor não foi acompanhado, inicialmente, de uma política pública com preocupações socioambientais, o que só veio ocorrer de forma mais efetiva a partir da metade da década de 90 . Percebe-se uma trajetória titubeante no planejamento governamental do setor, o que tem acarretado uma série de impactos negativos, em especial em relação ao meio ambiente e à preservação da cultura das comunidades receptoras.

Com base na necessidade de melhorias no planejamento das políticas e das ações públicas relacionadas à interface entre turismo e sustentabilidade é que este trabalho teve origem. Possui como objetivo descortinar a evolução e o desenvolvimento das atividades do turismo no Brasil, mediante apresentação de um panorama das políticas de gestão pública do setor, bem como dos programas voltados para um turismo sustentável. Foi guiado pela busca de entendimento sobre a relação entre os benefícios e os impactos gerados pelo turismo, e partiu do seguinte questionamento: será que as políticas públicas do turismo no país têm se apresentado como um instrumento de indução, a fim de que este se constitua em um fenômeno econômico-social que extrapole seu próprio crescimento e gere desenvolvimento, adotando uma postura sustentável?

Procurou-se gerar reflexões sobre o planejamento de um turismo capaz de conciliar em seu crescimento aspectos econômicos, sociais e ambientais e, desta forma, representar desenvolvimento para os territórios nos quais se implanta. Apresenta-se como possível caminho a seguir nesse sentido os estímulos para obtenção de certificação em sustentabilidade por parte das organizações empresariais que atuam no setor.

O texto foi organizado em mais quatro seções, além desta introdução. A próxima apresenta os aspectos metodológicos empregados no estudo. A terceira unidade aborda a evolução histórica e o cenário macroeconômico do turismo no Brasil e no mundo. A quarta seção traz as políticas públicas para o turismo no país e uma descrição dos programas governamentais focados na certificação em sustentabilidade no turismo. Por fim, uma última seção com as considerações finais do estudo.

\section{ASPECTOS METODOLÓGICOS}

Este trabalho consiste de um ensaio teórico-descritivo (qualitativo) sobre a evolução e as perspectivas de desenvolvimento do setor turístico nacional, mediante análise das políticas públicas, 
dos planos e dos programas que inter-relacionam turismo e sustentabilidade, com vistas a um turismo sustentável (econômico, social e ambiental). Foi utilizada pesquisa bibliográfica e documental para obtenção dos dados e das informações secundárias sobre a evolução histórica do turismo no mundo e no Brasil, porém o foco foi sobre as ações governamentais de gestão do setor no país nas décadas de 1990 e 2000, a partir de sites, documentos, legislações e estudos publicados em eventos e periódicos científicos.

Deste modo, foram abordados os principais programas públicos voltados à melhoria das condições e do desenvolvimento do turismo nacional, desde a década de 1990, como o Programa Nacional de Municipalização do Turismo (PNMT). Também foram apresentados aspectos, objetivos e resultados dos Planos Nacionais do Turismo (PNT) relativos aos períodos de 2003-2007 e 2007-2010, além de perspectivas para os anos de 2011-2014. Houve estudo também inerente à condução e aos resultados dos PNT e quanto aos programas públicos mais recentes voltados ao turismo, surgidos na década passada, tais como: Programa de Certificação em Turismo Sustentável (PCTS); Programa Bem Receber; Programa Turismo 100\%; e Programa Bem Receber Copa. Estes programas foram selecionados por incluírem questões relativas à sustentabilidade, ou seja, intencionam tornar as organizações do setor mais sustentáveis, de modo que estes são apresentados em seus objetivos, aspectos e efeitos relativos ao estabelecimento de normas de certificação em sustentabilidade para o turismo no país.

\section{EVOLUÇÃO DO TURISMO NO MUNDO E NO BRASIL}

\section{DADOS RELATIVOS AO SETOR DE TURISMO}

O fluxo de turistas mundial ao longo da segunda metade do século XX teve um crescimento contínuo e quase duplicou a cada década, de 25 milhões em 1950 passou a 456 milhões em 1990 (OMT, 2001), alcançou 689 milhões em 2000 e chegou em 2010 ao montante de 940 milhões (INSTITUTO BRASILEIRO DE TURISMO [EMBRATUR], 2011). Todo esse crescimento ocasionou impactos multiplicativos em outros setores econômicos devido ao fluxo de mercadorias, geração de renda, pagamento de salários e arrecadação de impostos, dentre outros.

Ao longo da evolução das políticas públicas para o turismo no mundo, podem ser identificados dois diferentes momentos. Em uma primeira etapa, iniciada por volta dos anos de 1950, houve uma preocupação com o aumento do fluxo de turistas e que coincidiu com a explosão do chamado 'turismo de massa', que resultou em políticas de cunho quantitativas e com foco imediatista e econômico. A lógica empregada é consoante com a afirmação de Silveira (2005) de que a sustentabilidade do turismo tem recebido uma prioridade secundária se comparada com a busca do lucro e do crescimento no curto prazo, na visão dos agentes econômicos e responsáveis pela formulação de políticas turísticas por todo o mundo. Práticas que em verdade buscaram apropriar-se dos lugares (destinos) para aumentar a participação no mercado e atender aos desejos e aos interesses da demanda turística, quase sem considerar as necessidades das populações locais e do meio ambiente.

Num segundo estágio, a partir de fins da década de 1970, surgiram preocupações relativas à qualidade da atividade turística e do desenvolvimento equilibrado do setor, por meio da conservação dos recursos naturais, sociais e culturais que lhe dão sustentação, ou seja, uma abordagem mais qualitativa e de longo prazo (OMT, 2001).

Na primeira década deste milênio, o turismo cresceu a uma média de 3,23\% de chegadas de turistas e de $6,97 \%$ na receita cambial no mundo, como mostra a Tabela 1 . Houve aumento do setor em quase todos os anos, com exceção de 2001, 2003 e 2009 com variações negativas no fluxo turístico e, em 2001 e 2009, na receita cambial gerada. Tais retrações podem ter ocorrido devido aos ataques terroristas nos Estados Unidos (EUA), aos surtos gripais epidêmicos e às crises econômicas globais. O ano de 2010 foi o de maior fluxo de turistas da história (940,0 milhões) e o de 2008 foi o que gerou maior receita global (US\$941,7 bilhões), quase o dobro de 2001. 
Tabela 1: Fluxo de turistas internacionais e receita cambial no mundo

\begin{tabular}{lccccccccccc}
\hline ITEM & 2001 & 2002 & 2003 & 2004 & 2005 & 2006 & 2007 & 2008 & 2009 & 2010 & $\begin{array}{l}\text { MÉ- } \\
\text { DIA }\end{array}$ \\
\hline $\begin{array}{l}\text { Fluxo turísti- } \\
\text { co (milhão) }\end{array}$ & 688,5 & 708,9 & 696,6 & 765,5 & 801,6 & 846,0 & 900,5 & 919,0 & 880,5 & 940,0 & 814,7 \\
\hline $\begin{array}{l}\text { Va riaçã o } \\
\text { (\%) }\end{array}$ & $-0,10$ & 2,96 & $-1,74$ & 9,89 & 4,72 & 5,54 & 6,44 & 2,05 & $-4,19$ & 6,76 & 3,23 \\
\hline $\begin{array}{l}\text { Receita cam- } \\
\text { bial (US\$ bil- } \\
\text { hão) }\end{array}$ & 471,6 & 474,2 & 525,1 & 632,7 & 678,7 & 744,0 & 857,4 & 941,7 & 852,4 & 919,0 & 709,7 \\
\hline $\begin{array}{l}\text { Va ri a çã o } \\
\text { (\%) }\end{array}$ & $-2,34$ & 0,55 & 10,73 & 20,49 & 7,26 & 9,63 & 15,24 & 9,83 & $-9,48$ & 7,81 & 6,97 \\
\hline
\end{tabular}

Fonte: Elaborado a partir de Ministério do Turismo (MTur) (2011) e EMBRATUR (2011).

A Europa sempre foi a região de maior fluxo de turistas e em 2010 recebeu 476,7 milhões de visitantes, a metade de todas as chegadas mundiais (50,4\%). A seguir, tem-se: a Ásia e o Pacífico, com 203,8 milhões (21,8\%), as Américas, com 149,8 milhões (16,2\%), o Oriente Médio, com 60,3 milhões $(6,4 \%)$ e a África com 49,2 milhões (5,2\%). Os principais destinos turísticos no ano foram: França, EUA, China e Espanha (EMBRATUR, 2011).

\section{PERSPECTIVAS PARA O SETOR DE TURISMO}

De acordo com a OMT (2001), existe estimativa de forte expansão do setor de turismo para 2020, com um fluxo mundial de turistas de cerca de 1,6 bilhões. Os principais países emissores serão Alemanha, Japão, EUA, China e Reino Unido, que juntos responderão por $40 \%$ deste total. Os destinos turísticos mais visitados serão China, EUA, França, Espanha e Hong-Kong, que receberão $28,9 \%$ do fluxo total. Essas previsões sofrerão influência de variáveis (de demanda, de oferta, demográficas, políticas, econômicas, sociais, tecnológicas, dentre outras) no decorrer do tempo. Contudo, existe uma grande certeza quanto ao fato de que o crescimento do turismo mundial estará atrelado à obtenção da sustentabilidade das atividades turísticas, pois o turismo é "vulnerável às mudanças do entorno natural, cultural e econômico, assim como a qualquer variação e incidente que aconteça nos limites de uma região" (OMT, 2001, p. 243).

Para o World Travel \& Tourism Council (WTTC) (2012), as previsões para o turismo mundial e para o Brasil no ano de 2021 mostram ser bastante positivas no tocante à atividade econômica gerada pelo setor, conforme mostrado na Tabela 2.

Tabela 2: Contribuição esperada do turismo para o mundo e o Brasil em 2021

\begin{tabular}{lllll}
\hline FATORES & MUNDO & \multicolumn{2}{l}{ BRASIL } \\
\hline Contribuição Direta ao PIB & US\$ $2.860,5$ bilhões & $2,9 \%$ & R\$ 206,9 bilhões & $3,6 \%$ \\
\hline Contribuição Total ao PIB & US\$ 9.226,9 bilhões & $9,6 \%$ & R\$ 555,1 bilhões & $9,5 \%$ \\
\hline Contribuição Direta ao Emprego & 120,43 milhões & $3,6 \%$ & 3,56 milhões & $3,2 \%$ \\
\hline Contribuição Total ao Emprego & 323,83 milhões & $9,7 \%$ & 9,75 milhões & $8,9 \%$ \\
\hline Exportações do turismo & US\$ $1.789,2$ bilhões & $4,7 \%$ & R\$ 38,7 bilhões & $3,5 \%$ \\
\hline Investimento & US\$ $1.487,9$ bilhões & $4,6 \%$ & R\$ 89,3 bilhões & $6,3 \%$ \\
\hline
\end{tabular}

Fonte: Elaborado a partir de WTTC (2012).

A Tabela 2 apresenta expectativas de incremento para todos os fatores elencados: contribuição direta ao Produto Interno Bruto (PIB), gerada pelos segmentos que tratam diretamente com os turistas (hotéis, agentes de viagens, companhias aéreas, outros serviços de transporte de passageiros, restaurantes e de lazer); contribuição total ao PIB, com a soma da contribuição direta 
com a produção indireta induzida pelo turismo; contribuição direta ao emprego pelo número de postos de trabalho no setor; contribuição total ao emprego com a soma dos postos de trabalhos diretos e indiretos derivados das atividades turísticas; exportações do turismo devido à soma das despesas no âmbito de um país efetuadas por turistas internacionais em suas viagens, incluindo as despesas de transporte; e investimento como o montante a ser investido no setor de turismo.

A análise dos dados constantes nas Tabelas 1 e 2, sobre a evolução e as perspectivas para o setor de turismo, demonstra sua importância para a economia mundial, que pode chegar a um total próximo a US\$ 10 trilhões de contribuição total para o PIB e para a geração de 320 milhões de empregos. Quanto ao Brasil, as perspectivas também são bastante positivas, com mais de meio trilhão de reais de contribuição ao PIB e 10 milhões de postos de trabalho diretos e indiretos gerados pelo setor de turismo.

\section{A EVOLUÇÃO DO TURISMO NO BRASIL}

No Brasil, o turismo já consiste em uma atividade econômica de grande importância e que possui como características principais: intersetorialidade, captação de investimentos e geração de empregos e renda. Inclui-se entre os setores que poderiam se constituir nas forças motrizes do desenvolvimento nacional. Porém, só passou a ser entendido como segmento econômico nos anos de 1970, com um crescimento significativo em face do turismo de massa para destinos com belezas naturais, riqueza em biodiversidade e biomas e diversidade étnico-cultural. A Tabela 3 traz a evolução de chegadas de turistas estrangeiros no país nas últimas décadas:

Tabela 3: Fluxo de turistas estrangeiros no Brasil de 1970 a 2009

\begin{tabular}{llllllll}
\hline ANO & TURISTAS & ANO & TURISTAS & ANO & TURISTAS & ANO & TURISTAS \\
\hline 1970 & 249.900 & 1980 & 1.625 .422 & 1990 & 1.091 .067 & 2000 & 5.313 .463 \\
\hline 1971 & 287.926 & 1981 & 1.357 .879 & 1991 & 1.228 .178 & 2001 & 4.772 .575 \\
\hline 1972 & 342.961 & 1982 & 1.146 .681 & 1992 & 1.692 .078 & 2002 & 3.784 .898 \\
\hline 1973 & 399.127 & 1983 & 1.420 .481 & 1993 & 1.641 .138 & 2003 & 4.132 .847 \\
\hline 1974 & 480.267 & 1984 & 1.595 .726 & 1994 & 1.853 .301 & 2004 & 4.793 .703 \\
\hline 1975 & 517.967 & 1985 & 1.735 .982 & 1995 & 1.991 .416 & 2005 & 5.358 .170 \\
\hline 1976 & 555.967 & 1986 & 1.934 .091 & 1996 & 2.665 .508 & 2006 & 5.017 .251 \\
\hline 1977 & 634.595 & 1987 & 1.929 .053 & 1997 & 2.849 .750 & 2007 & 5.025 .834 \\
\hline 1978 & 784.316 & 1988 & 1.742 .939 & 1998 & 4.818 .084 & 2008 & 5.050 .099 \\
\hline 1979 & 1.081 .799 & 1989 & 1.402 .897 & 1999 & 5.107 .169 & 2009 & 4.802 .217 \\
\hline MÉDIA & 533.483 & MÉDIA & 1.589 .115 & MÉDIA & 2.493 .769 & MÉDIA & $\mathbf{4 . 8 0 5 . 1 0 6}$ \\
\hline
\end{tabular}

Fonte: Elaborado a partir de MTur (2011).

Os números apresentados na Tabela 3 mostram que, em 1970, ocorreram 250 mil chegadas de turistas estrangeiros, e passou para mais de um milhão e meio em 1980, ou seja, em apenas 10 anos houve um incremento de 500\%. Há que se notar que foi um período de descoberta da prática de turismo na região Nordeste do país, como grande atrativo aos turistas europeus. Em seguida, houve um breve período de queda (1981 e 1982), mas logo ocorreu boa recuperação que levou a quase 2 milhões de turistas em 1987. O período de 1988 a 1991 foi marcado por forte retração no fluxo de turistas, com uma queda de quase um milhão de chegadas em 1990. Há que se destacar que este foi um período conturbado para a economia nacional, com um surto de hiperinflação monetária marcado por fortes planos econômicos e pela abertura comercial do país, que podem ter influenciado a vinda de turistas internacionais.

A partir de 1992, o turismo no país experimentou um novo impulso, que durou quase dez anos, devido a fatores como: aumento de renda da população; consolidação da democracia; abertura da economia; divulgação na mídia mundial gerada pela realização da Conferência das Nações Unidas sobre Meio Ambiente e Desenvolvimento/Rio-92; estabilidade monetária com o Plano Real; 
e ampliação da rede de hospedagem, resorts, parques e empreendimentos de lazer (BENI, 2007). No início deste século, ocorreu um período de instabilidade no fluxo turístico no país, com retrações nos anos de 2001 e 2002. Porém, a partir de 2003 o número de turistas estrangeiros evoluiu e estabilizou-se em cerca de 5 milhões de chegadas ao final da década e com média de 4,8 milhões no período. Os dados referentes ao período de 2001 a 2010, como geração de receita cambial, participação no fluxo turístico mundial e desembarques domésticos, mostram estas tendências e são apresentados na Tabela 4.

Tabela 4: Participação do Brasil no fluxo turístico mundial e nos desembarques nacionais

\begin{tabular}{|c|c|c|c|c|c|c|c|c|c|c|c|}
\hline ITEM & 옹 & ปั & m & ষ্ণ & $\stackrel{\text { ㅇ }}{\text { ํ }}$ & ঃ & ò & $\stackrel{\infty}{\circ}$ & \&̊̀ & 움 & $\begin{array}{l}\text { M É - } \\
\text { DIA }\end{array}$ \\
\hline $\begin{array}{c}\text { Receita } \\
\text { cambial } \\
\text { (US\$ bilhão) }\end{array}$ & 1,70 & 2,00 & 2,48 & 3,22 & 3,86 & 4,32 & 4,95 & 5,79 & 5,31 & 5,92 & 3,96 \\
\hline $\begin{array}{c}\text { Variação } \\
(\%)\end{array}$ & - & 17,65 & 24,00 & 29,84 & 19,88 & 11,92 & 14,58 & 16,97 & $-8,29$ & 11,49 & 15,34 \\
\hline $\begin{array}{c}\text { Brasil no } \\
\text { turismo } \\
\text { mundial }(\%)\end{array}$ & 0,69 & 0,53 & 0,59 & 0,63 & 0,67 & 0,59 & 0,56 & 0,55 & 0,55 & 0,54 & 0,59 \\
\hline $\begin{array}{l}\text { Desem- } \\
\text { barques } \\
\text { nacionais } \\
\text { (milhão) }\end{array}$ & 32,62 & 32,95 & 30,74 & 36,55 & 43,10 & 46,35 & 50,00 & 48,70 & 56,02 & 68,26 & 44,53 \\
\hline $\begin{array}{c}\text { Variação } \\
(\%)\end{array}$ & - & 1,01 & $-6,71$ & 18,90 & 17,92 & 7,54 & 7,87 & $-2,60$ & 15,03 & 21,85 & 8,98 \\
\hline
\end{tabular}

Fonte: Elaborado a partir de MTur (2011) e EMBRATUR (2011).

A Tabela 4 permite visualizar duas situações contrastantes quanto à atividade turística no país. De um lado, houve crescimento constante na receita cambial gerada pelo setor, que iniciou o decênio com US $\$ 1,7$ bilhão e terminou com US $\$ 5,92$ bilhões e teve média anual de quase US $\$ 4$ bilhões. O número de desembarques em voos domésticos subiu de quase 33 milhões para 68 milhões de passageiros, com forte tendência de crescimento desde 2005, mesmo com variações negativas em 2003 e 2008, derivadas de problemas enfrentados pelo turismo no âmbito mundial. De outro, ocorreu redução da participação do país no total mundial de 0,70\% para 0,54\%, com média em 0,59\%, que denota que a participação do país no fluxo turístico mundial oscilou pouco acima de meio por cento, mas apresentou tendência de queda durante quase todo o período (SOUZA; FERREIRA, 2011).

No ano de 2010, o número de turistas estrangeiros no país foi de 5.161 .379 chegadas, com um crescimento de 7,5\% em relação ao ano anterior. Desse total, 27,1\% vieram da Argentina e 18,0\% de outros países da América do Sul (Uruguai, Paraguai e Chile, principalmente), enquanto 30,0\% são oriundos da Europa, com destaque para Itália, Alemanha, França, Portugal e Espanha e, ainda, $12,5 \%$ dos EUA. Os motivos de viagem foram: lazer ( $46,1 \%)$; negócios e eventos (23,3\%); e outros motivos $(30,6 \%)$. Como meio de chegada ao país, destacam-se o transporte aéreo $(69,9 \%)$ e o terrestre $(27,1 \%)$. Os destinos preferidos no país foram os estados de São Paulo $(39,0 \%)$, Rio de Janeiro $(19,0 \%)$, Paraná $(14,0 \%)$ e Rio Grande do Sul $(12,7 \%)$, que responderam por $88,8 \%$ das chegadas. Os meses de maior afluxo foram janeiro, fevereiro, março e dezembro, que somaram 45,9\% de todo o movimento no ano (MTUR, 2011; EMBRATUR, 2011).

\section{PERSPECTIVAS E DÚVIDAS QUANTO AO SETOR DO TURISMO NO BRASIL}

O turismo no Brasil cresce em arrecadação, movimentação econômica e fluxo de viajantes, porém em um ritmo abaixo do nível mundial. Além disto, não tem alcançado um desenvolvimento 
correspondente para que as populações residentes consigam auferir os benefícios gerados e não atingiu um patamar considerado como sustentável, ou seja, planejado de modo coerente e preventivo por meio da participação e do envolvimento das comunidades, da iniciativa privada e dos órgãos governamentais, com vistas à obtenção de melhorias duradouras para as regiões ou as destinações. Falta-Ihe a mensuração da viabilidade, das consequências futuras e da preocupação com a formação de uma sociedade consciente quanto à conservação dos recursos naturais essenciais ao turismo.

É fato que alguns dos principais destinos turísticos do país se encontram a caminho de uma condição insustentável, pois almejaram um crescimento apenas econômico. Ignoraram ou não consideraram os riscos existentes de sua própria extinção face ao descaso com que tratam o meio ambiente, ou simplesmente relegaram este a um segundo plano. É preciso compreender que "os atrativos naturais de um destino turístico não são suficientes para manter um fluxo constante de visitantes" (SOUZA; FERREIRA, 2011, p. 2).

A Fundação Getúlio Vargas (FGV) e o MTur (2011) efetuaram estudo com executivos das 80 maiores empresas do setor no país, em busca de construir um cenário macroeconômico e das perspectivas de desenvolvimento dos negócios e dos investimentos no turismo nacional, face aos megaeventos previstos para o país, como: a Conferência em Desenvolvimento Sustentável (Rio+20), a Copa do Mundo de Futebol, os Jogos Olímpicos e Paraolímpicos. Os resultados apontaram crescimento em termos de receitas auferidas e de quadro de pessoal em 2010 em todos os segmentos pesquisados (agências de viagens, eventos, feiras, locadoras de automóveis, meios de hospedagem, operadoras de turismo, transporte aéreo e rodoviário), com exceção do turismo receptivo. Tal fato se deveu ao incremento do turismo interno e à valorização da moeda nacional que gerou aumento das vendas para destinos internacionais e também a redução da entrada de turistas estrangeiros (FGV; MTUR, 2011).

As expectativas identificadas pelos empresários em relação à evolução do setor do turismo nacional são positivas devido a uma série de fatores, tais como: a continuidade das políticas de governo e o crescimento econômico; o aumento dos investimentos estrangeiros e da exposição do país na mídia internacional e nacional; a expansão da oferta e da qualidade dos meios de hospedagem; a ampliação da capacidade das agências de viagens, com adoção de ferramentas tecnológicas; a expansão da rede de vendas das operadoras de turismo; o lançamento de feiras e eventos em cidades médias; e a majoração geral do faturamento, dos preços, dos custos e dos quadros de pessoal. Como fatores negativos que devem ser objeto de maior atenção por parte dos que atuam no setor estão: a desvalorização do Real, os entraves da burocracia administrativa e a escassez de trabalhadores qualificados (FGV; MTUR, 2011).

Torna-se relevante, então, para a continuidade e para a sustentabilidade do turismo nacional, que as políticas públicas que norteiam seu desenvolvimento consigam captar e incluir aspectos relativos ao meio ambiente e à sociedade, além dos ligados ao crescimento econômico. Contudo, será que a condução das políticas e dos programas nacionais do turismo condiz com esse modo de pensar? Será que incorporam a atual relevância dos conceitos de sustentabilidade ambiental e social ao apontar os caminhos futuros para o setor no país? Na busca de respostas para estes questionamentos, segue uma seção sobre as políticas públicas de desenvolvimento do turismo nacional e os programas federais criados para estimular a inclusão da sustentabilidade nas atividades de turismo no país.

\section{POLÍTICAS PÚBLICAS PARA SUSTENTABILIDADE DO TURISMO NO BRASIL}

\section{VISÃO HISTÓRICA DAS POLÍTICAS PARA O SETOR DO TURISMO NO PAÍS}

Ao longo de sua história no Brasil, o setor do turismo tem recebido pouca atenção governamental e foi tido como uma atividade de menor monta e preocupação em relação à indústria e à agricultura, por exemplo. Somente em 1966 é que foi definida uma política nacional para o setor, por meio do decreto Lei no 55/1966, e criou o Conselho Nacional de Turismo (CNTur) e a Empresa Brasileira de Turismo (Embratur) (NOIA; VIEIRA JÚNIOR; KUSHANO, 2007). A partir dos anos de 1970 iniciouse uma articulação de gestão do setor, que era subordinado ao então Ministério da Indústria e do Comércio; e a criação do Fundo Geral do Turismo (Fungetur), para financiar o crescimento do turismo nacional (DIAS, 2003). 
No início da década de 1990 foi editada nova legislação para o setor, com a Lei 8.181/1991 (MDIC, 2012), e a transformação da Embratur como autarquia, com nova denominação para Instituto Brasileiro de Turismo e foco na formulação, na coordenação e na execução do planejamento do turismo (DIAS, 2003). Contudo, não houve uma evolução concreta da gestão pública do setor no país, pois pouco se avançou. Grande parte desta estagnação em termos de políticas públicas para o setor pode ser atribuída à instabilidade política e econômica do país no período. Outro fato foi que o setor do turismo sempre foi tratado num plano nacional, macro e centralizado na esfera federal.

Somente na metade da década de 1990 é que de fato surgiram mudanças favoráveis na condução do turismo no país, com a elaboração de uma nova política nacional e a criação de programas que se constituíram em marcos de um novo olhar governamental para o setor dentro uma política nacional de turismo (1993-1996), tais como: Programa de Ação para o Desenvolvimento do Turismo no Nordeste (Prodetur-NE), Programa Nacional de Ecoturismo e Programa Nacional de Municipalização do Turismo (PNMT) (DIAS, 2003).

O PNMT foi lançado em 1994 com uma abordagem que buscava o desenvolvimento do turismo a partir da transferência de sua responsabilidade para o nível municipal/local e estruturação em 5 princípios norteadores - descentralização, sustentabilidade, parcerias, capacitação e mobilização. Houve estímulos à criação de conselhos e de fundos municipais que fossem capazes de captar as necessidades e as especificidades de cada destino turístico em particular e de modo descentralizado (NOIA; VIEIRA JÚNIOR; KUSHANO, 2007). O programa ajudou a impulsionar o turismo mediante a conscientização, a preparação e a capacitação das comunidades e das localidades no país (GALDINO; COSTA, 2011).

Os efeitos do PNMT somente foram potencializados na década seguinte, quando serviu como base para a criação de medidas relacionadas às políticas e aos planos de turismo de caráter nacional e trouxe benefícios expressivos aos municípios que adotaram sua prática. Nesta época ocorreram esforços do Governo Federal para estimular, organizar e impulsionar o setor turístico mediante políticas, programas e planos voltados para envolver seus diversos atores e órgãos (investidores, empresários, especuladores imobiliários, governos municipais e estaduais e outros), como será visto adiante. O setor passou a ser considerado como um dos mais importantes geradores de desenvolvimento socioeconômico (SOUZA; FERREIRA, 2011).

A mudança no governo federal ocorrida no Brasil em 2002 trouxe um novo panorama para o setor no país, ao adotar medidas para dar maior destaque ao turismo, como: a criação do Ministério do Turismo (MTur) e a reformulação da Embratur, que passou a ser responsável pela execução da Política Nacional de Turismo. O objetivo foi ampliar o fluxo turístico no que tange à promoção; ao marketing; e ao apoio à comercialização dos destinos, dos serviços e dos produtos turísticos brasileiros no mercado internacional (EMBRATUR, 2011).

O Ministério do Turismo passou a ser o articulador do processo de integração dos diferentes segmentos do setor turístico junto aos governos federal, estaduais e municipais, poder legislativo, setor empresarial e sociedade organizada, bem como entre as políticas públicas e o setor privado. Coube ao MTur estabelecer a Política Nacional de Turismo e elaborar os Planos Nacionais do Turismo (PNT) e dentre suas obrigações foi incluída a proteção do meio ambiente, da biodiversidade e do patrimônio cultural de interesse turístico. Além disto, coube atenuar passivos socioambientais provocados pela atividade turística e estimular a prática do turismo responsável em áreas naturais protegidas ou não (MTUR, 2003).

Para Sonsolo e Cruz (2003), o governo apressou-se em elaborar um plano de ação para o turismo, porém não explicitou sob qual política pública este foi traçado. Movimento em sentido contrário ao adotado pela gestão anterior, em que havia uma política explícita para o setor, porém que carecia de planos de ação. Isto significou uma perda de conteúdo e norteamento para o turismo nacional. Mais uma vez registrou-se a falta de planejamento da gestão pública do setor e da congruência entre as políticas e os planos de governo. Também cabe registrar que, se por um lado ocorreu a elevação de importância dada ao setor, de outro houve o abandono dos rumos de municipalização contidos no PNMT para uma nova visão focada na regionalização do turismo.

Nos anos seguintes outros fatos marcaram as mudanças ocorridas no turismo nacional, que incluem: a busca por contemplar diversidades regionais, culturais e naturais, e proporcionar a expansão do mercado turístico interno e a inserção do Brasil no cenário mundial; a promulgação da Lei no 11.771/2008 (Lei Geral do Turismo), que conceituou o turismo no país como instrumento de 
desenvolvimento econômico e social, promoção e diversidade cultural e preservação da biodiversidade ao gerar movimentação econômica, trabalho, emprego, renda e receitas públicas; e a implantação do Sistema Nacional de Cadastramento, Classificação e Fiscalização dos Prestadores de Serviços Turísticos (Sisnatur), para identificar e promover o ordenamento, a formalização e a legalização dos prestadores de serviços da cadeia produtiva do turismo (BRASIL, 2012). Tais iniciativas basearam-se nos Planos Nacionais do Turismo (PNT), assim cabe análise sobre no que consistem seus objetivos e resultados alcançados.

\section{PLANOS NACIONAIS DO TURISMO (PNT)}

Os PNT consistem em planos quadrienais de caráter participativo que apresentam as diretrizes, as metas e os programas regulatórios e fiscalizatórios com fins de explicitar os ideais do governo e do setor produtivo e orientar ações necessárias para consolidar o desenvolvimento do turismo em um novo padrão. Padrão este que possa integrar as regiões com o aumento da competitividade, impactar na melhoria das condições de vida da população, descentralizar as decisões e respeitar o meio ambiente (MTUR, 2003).

A elaboração dos PNT ocorreu por meio de diagnósticos para identificação dos principais problemas e fatores limitantes do crescimento do turismo no país, tais como: ausência de processos avaliativos dos resultados das políticas e planos implantados no setor; insuficiência de dados, informações e pesquisas sobre o turismo no país; deficiência na qualificação profissional no setor (gerencial e operacional); deficiência na infraestrutura turística básica (saneamento, água, energia e transporte) (SOUZA; FERREIRA, 2011); oferta de crédito insuficiente e inadequada para o setor; baixa qualidade e pouca diversidade de produtos turísticos ofertados para o mercado; e insuficiência de recursos e falta de estratégia e articulação na promoção e na comercialização do produto turístico brasileiro (MTUR, 2003).

O primeiro PNT referiu-se ao período de 2003-2007 e objetivou desenvolver produtos turísticos brasileiros que contemplassem as diversidades regionais, culturais e naturais, bem como estimulassem e facilitassem seu consumo nos mercados nacional e internacional. Foram traçadas as seguintes metas para o período: gerar 1,2 milhões de novos empregos e ocupações; gerar U $\$ 8$ bilhões em divisas; ampliar a oferta turística brasileira com o desenvolvimento de pelo menos 3 produtos de qualidade em cada Estado e no Distrito Federal; aumentar o fluxo de turistas estrangeiros para 9 milhões e para 65 milhões de passageiros em voos domésticos (MTUR, 2003). Metas traçadas com o intuito de gerar benefícios não somente para as atividades de turismo, mas também para o crescimento de toda a sociedade sob as melhores perspectivas de vida (GALDINO; COSTA, 2011).

As metas foram definidas para serem alcançadas por meio de macroprogramas voltados a atingir o equilíbrio e a continuidade do crescimento do setor, com os objetivos de: gestão de relações institucionais; fomento; infraestrutura; estruturação e diversificação da oferta turística; qualidade dos produtos turísticos; promoção e apoio à comercialização; e informações turísticas (MTUR, 2003). Contudo, o enfoque econômico preponderou na elaboração do PNT.

Noia, Vieira Junior e Kushano (2007) afirmam que o momento de elaboração e execução do PNT 2003-2007 foi adequado devido aos esforços desenvolvidos no governo anterior para capacitação profissional, qualidade das destinações e da municipalização do turismo. Porém, efetuam diversas críticas quanto a: não sinalização clara quanto à metodologia utilizada; não explicitação do grau de participação dos diferentes segmentos do turismo nacional; ausência de representação de organizações acadêmicas e de direitos do consumidor; insuficiência de dados quanto à participação do setor no PIB; falta de diagnósticos regionalizados; objetivos abrangentes e sem sinalizar sua forma de operacionalização; metas globais e generalizadas; inexistência de referências quanto às fontes de financiamentos para a efetivação das metas e à participação da iniciativa privada; e falta de atribuição de responsabilidades para as empresas e para o setor público no plano. Além disto, os autores questionam se os agentes multiplicadores e gestores do turismo possuem capacitação para atuarem no setor, pois a maioria não possui formação na área, inclusive dentro dos quadros do próprio MTur.

A elaboração das metas do PNT 2003-2007 se deu em um momento em que o mundo sentia os fortes efeitos dos atentados terroristas de 2001 nos Estados Unidos. O turismo foi um dos setores econômicos mais atingidos, com significante retração no mundo inteiro e reflexos no Brasil, assim as metas traçadas não foram alcançadas. Os dados apresentados na Tabela 3 quanto ao fluxo de 
turistas estrangeiros no período de 2003-2007, com pouco mais de 5,3 milhões em 2005, mesmo patamar atingido em 2000, e na Tabela 4 quanto ao número de desembarques nacionais com um máximo de 50 milhões em 2007, demonstram o contraste ante as metas estabelecidas (9 milhões de fluxo de turistas estrangeiros e de 65 milhões de passageiros domésticos).

No segundo PNT (2007-2010) houve a incorporação do objetivo geral de promover o turismo como fator de inclusão social, por meio da geração de trabalho e renda e da inclusão da atividade na pauta de consumo de todos os brasileiros, para fins de proporcionar à população melhores condições de realização da prática de turismo. Foram traçadas metas para aumentar o número das viagens de modo a: promover a realização de 217 milhões de viagens no mercado interno; criar 1,7 milhões de novos empregos e ocupações; estruturar 65 destinos turísticos selecionados com padrão de qualidade internacional; e gerar 7,7 bilhões de dólares de divisas (MTUR, 2007).

Novamente as metas definidas no PNT não foram atingidas, pois a receita cambial em 2010 ficou abaixo de US $\$ 6$ bilhões e as chegadas internacionais em 5 milhões. Os destinos selecionados pouco avançaram de modo concreto na atração de turistas e os números de novos empregos e de qualificação dos trabalhadores no setor pouco avançaram. Para Souza e Ferreira (2011), as metas foram superdimensionadas e não consideraram as tendências do turismo, além de somente incorporarem as dimensões de sustentabilidade econômica, social e espacial. Desconsideraram outras dimensões do turismo, como a política, a ecológica, a cultural, etc. Em consequência, o retorno dos investimentos não se concretizou, fato que gerou desaceleração da atividade econômica, desemprego e impactou no desenvolvimento local e nas dimensões da sustentabilidade ao gerar expectativas que não se realizaram.

O terceiro PNT, referente ao período de 2011/2014, apresenta orientações estratégicas para o desenvolvimento da atividade turística e tem como um dos seus pilares direcionar esforços e investimentos em ações que contribuam para erradicação da pobreza no país. Suas diretrizes visam promover a inclusão social, com a execução de projetos para a geração de negócios, de emprego e renda para a população. O plano tem como premissas: ampliar o diálogo com a sociedade, reduzir as desigualdades regionais, promover a sustentabilidade, incentivar a inovação e promover a regionalização do turismo. Estabelece objetivos ligados ao turismo nacional no que tange: à preparação para os grandes eventos, como a Copa do Mundo e as Olimpíadas; à qualificação de 306 mil profissionais; ao incentivar ao turismo interno; ao incremento da geração de divisas internacionais; ao aumento da competitividade; e ao fortalecimento da gestão compartilhada (MTUR, 2012).

Para Galdino e Costa (2011), os PNT foram elaborados sem considerar aspectos relevantes da realidade nacional (diversidades regionais, ambientais, climáticas, sociais, econômicas, políticas e culturais, dentre outras), que, por sua vez, também não estava estruturada para suportar o crescimento e o desenvolvimento propostos para o turismo no país. Tal condição, aliada à falta de eficiência, sinergia e comprometimento do poder público na aplicação das ações previstas, gerou a não concretização das metas e dos objetivos.

Souza e Ferreira (2011) afirmam que o foco do planejamento do turismo nacional está mais na elaboração de planos do que no monitoramento do processo de implantação, que é o responsável pelo alcance das metas estabelecidas. O planejamento continua a ocorrer numa visão negocial de curto-médio prazo, com foco em investimentos que beneficiam empreendimentos de alto valor e ignoram questões ligadas às necessidades das comunidades anfitriãs, aos interesses dos empresários de pequeno porte e à preservação dos recursos ambientais, sociais e culturais. Também, não considera a participação dos atores da sociedade na indicação das potencialidades e das limitações locais relacionadas ao setor turístico.

Galdino e Costa (2011) apontam que a falta de capacitação e as ingerências políticas são fatores relevantes que dificultam o desenvolvimento do setor do turismo no país. Sobre a falta de capacitação, é nítida a deficiência técnica e de conhecimentos específicos de turismo dos profissionais que atuam na gestão pública do setor, fato que interfere na elaboração e na implementação de ações que propiciam suporte aos planos e aos programas públicos. No plano político, a grande dificuldade consiste na diversidade partidária e de interesses no âmbito federal que afetam o setor, pois a distribuição da gestão de ministérios e autarquias não é realizada por meio de critérios técnicos e por competências, mas sim por meio de arranjos entre partidos que visam contemplar mais seus interesses políticos e pessoais, do que os interesses do país. Tais condições se repetem nos níveis estaduais e municipais, o que agrava ainda mais a situação do turismo nacional. 


\section{NORMAS DE CERTIFICAÇÃO EM SUSTENTABILIDADE PARA O TURISMO NACIONAL}

Um dos possíveis caminhos para conciliar os diferentes interesses envolvidos no setor do turismo e que possa atrelar questões econômicas, sociais e ambientais no seu desenvolvimento pode encontrar-se nos programas que objetivam certificar as organizações que adotam práticas sustentáveis em seus processos, produtos ou serviços. Swarbrooke (2000) alude que este é um dos principais instrumentos para uma atuação mais efetiva dos organismos públicos para estabelecer padrões oficiais de sustentabilidade ambiental do turismo. Padrões que possam auxiliar a demanda em seus processos de decisões de consumo de serviços turísticos mais sustentáveis e com isso acelerar os movimentos nesta direção por parte daquelas empresas do setor que procuram conscientizar os turistas sobre suas escolhas.

A adoção de sistemas de certificação socioambiental tem crescido de importância para a sobrevivência e para a ampliação de mercado de diversas atividades industriais e de prestação de serviços no mundo. Em vários setores econômicos (geração de energia, extração mineral, celulose e produção têxtil, dentre outros), a obtenção das certificações tornou-se condição sine qua non para uma organização adentrar e competir nos mercados mais desenvolvidos.

As primeiras iniciativas de normatização e certificação socioambiental surgiram nos países desenvolvidos entre fins da década de 1970 e os anos de 1990, como Alemanha, Canadá, EUA, Japão e países nórdicos. Tais iniciativas condiziam com o crescimento de uma opinião pública (consumidores e investidores) mais exigente e preocupada com o desenvolvimento sustentável. Nos países em desenvolvimento começaram a despontar nos anos de 1990, mediante adaptações nos programas existentes nos países industrializados. Para Bowman (2011, p. 270), o desenvolvimento e a implantação de uma certificação de turismo sustentável nos países pobres "is a process that can result in an important dialogue and policy-making process about the type of tourism development that a country wishes to pursue, greater awareness in the business community of the needs and generations".

O início da elaboração de normas de sustentabilidade para o turismo no país ocorreu em fins dos anos de 1990, fruto de uma parceria do governo federal com a Associação Brasileira de Normas Técnicas (ABNT), que gerou o Comitê Brasileiro de Normalização em Turismo - CB 54. O comitê ficou responsável pelo planejamento, coordenação e controle das normas relacionadas à terminologia, às ocupações e às competências de pessoal, produtos e serviços específicos ao setor de turismo, nos segmentos de: hotelaria, restaurantes e refeições coletivas, agenciamento e operação e demais funções do setor (ABNT, 2012).

O CB-54 elaborou 84 normas disponibilizadas integralmente por meio de acesso a um website gratuito e referentes a(o): Turismo de Aventura, Transporte, Competências Profissionais, Acessibilidade, Turismo Equestre, Serviços de Mergulho Recreativo, Cicloturismo e Meios de Hospedagem. Duas normas são voltadas para meios de hospedagem: Norma Brasileira de Referência (NBR) 15401:2006 (Meios de hospedagem - Sistema de gestão da sustentabilidade Requisitos); e a NBR 15333:2007 (Meios de hospedagem - Sistema de gestão da sustentabilidade - Requisitos de competências para auditores). A primeira traz requisitos e indicadores que possibilitam a todos os tipos e portes de organizações planejar e operar suas atividades de acordo com os princípios do turismo sustentável e propiciam informações quanto aos impactos ambientais, socioculturais e econômicos significativos para todas as partes interessadas. A segunda estabelece os requisitos aplicáveis de competência de auditores em sistemas de gestão da sustentabilidade (ABNT, 2012).

Apesar das normas de certificação em sustentabilidade para meios de hospedagem existirem há mais desde 2006, verifica-se que ainda não surtiram os efeitos desejados. O grau de adesão é ínfimo, pois de mais de 24 mil empresas que prestam serviços de alojamento no país (IBGE, 2012), apenas algumas centenas implantaram práticas sustentáveis e somente 6 obtiveram a certificação NBR15401 até setembro de 2012: Ville La Plage Pousada e Resort em Búzios/Rio de Janeiro; Hotel Canto das Águas e Hotel de Lençóis na Chapada Diamantina em Lençóis/Bahia; e Hotel Blumenberg, Hotel Dom Ramon e Pousada Encantos da Terra em Canela/RS. 


\section{PROGRAMAS GOVERNAMENTAIS PARA DESENVOLVIMENTO E SUSTENTABILIDADE DO TURISMO}

Para tornar a sustentabilidade um fator relevante no setor do turismo no Brasil não basta a elaboração ou a existência de normas e certificações. Devem existir programas e ações públicas contínuas que sirvam como chave para a conscientização quanto à sustentabilidade no turismo (SWARBROOKE, 2000) que incentivem e propiciem condições de esclarecimento e compreensão sobre os objetivos e os benefícios derivados da implantação de práticas sustentáveis e da obtenção de uma certificação por parte dos empreendimentos do setor. Dentre os programas públicos para o setor serão abordadas iniciativas que focaram dotar as empresas de maior consciência e atuação em prol da sustentabilidade socioambiental: Programa de Certificação em Turismo Sustentável (PCTS); Programa Bem Receber; Programa Turismo 100\%; e Programa Bem Receber Copa.

O PCTS surgiu em 2002 de uma parceria do MTur com o Instituto de Hospitalidade (IH) e o Conselho Brasileiro para o Turismo Sustentável (CBTS) para moldar um turismo sustentável e melhorar a qualidade e a competitividade do turismo nacional, com particular atenção às pequenas e às médias empresas. $A$ lógica foi difundir e consolidar práticas positivas de sustentabilidade, adoção de normas e implantação de um sistema de certificação para melhorar o desempenho nas dimensões da sustentabilidade (econômico, ambiental, cultural e social) nas empresas do setor (BARDDAL; ALBERTON; CAMPOS, 2010). Para Prochnow e Vasconcelos (2008), o programa objetivou o planejamento e a implementação de uma estratégia de certificação para os envolvidos na cadeia de turismo sustentável no Brasil, incluindo roteiros de ecoturismo, esportes de aventura e turismo convencional.

Cerca de 30 destinos turísticos prioritários para o turismo no país foram incluídos no programa e receberam ações para capacitação e para formação de auditores em sustentabilidade e de treinamentos e capacitações dos gestores e dos trabalhadores, com fornecimento de subsídio por parte do Governo Federal quanto às consultorias necessárias e ao processo de certificação em sustentabilidade. A lógica era incentivar e propagar a adoção de práticas sustentáveis e a certificação para que as empresas, principalmente meios de hospedagem, sejam mais sustentáveis em termos ambientais, sociais e econômicos.

As ações do PCTS foram interrompidas em meados de 2007 e como possíveis fatores de seu término estão: a falta de recursos financeiros e a complexidade, por ter diferentes organizações envolvidas nos destinos selecionados e que por sua vez possuíam características e condições de realização do turismo variadas. Além destas, também pode ser elencada a ausência de ações de marketing e de comunicação que consolidassem a marca do programa junto aos diversos stakeholders do setor e estimulassem o maior interesse, adesão e continuidade nos empreendimentos, bem como auxiliassem no seu acompanhamento e monitoramento.

Apesar da sua curta duração, as atividades do PCTS resultaram na formação de dezenas de auditores e centenas de consultores em gestão da sustentabilidade para atuarem como multiplicadores e na assistência técnica e capacitação de cerca de 600 empresas nos destinos escolhidos. O programa estimulou a elaboração de normas de certificação em sustentabilidade que recomendavam o atendimento de requisitos referentes às dimensões econômica, ambiental e sociocultural para o turismo sustentável (BARDDAL; ALBERTON; CAMPOS, 2010).

No mesmo ano foi lançado o Programa Bem Receber, parceria do MTur com o Serviço Brasileiro de Apoio às Micro e Pequenas Empresas (SEBRAE) e o IH. O objetivo foi contribuir para melhoria da qualidade dos serviços prestados e aumentar a competitividade do setor turístico, com base: na gestão sustentável, mediante consultoria para adoção de boas práticas de hospitalidade e sustentabilidade e apoio no alcance da certificação pela norma 15401:2006; e na qualificação profissional dos trabalhadores. O programa foi voltado para beneficiar meios de hospedagem de pequeno e médio porte, localizados em 30 destinos selecionados com base em fatores, como: fluxo de turistas, quantidade de empresas do setor, potencial de crescimento com base na perspectiva de investimentos e interesse local (IH; MTUR, 2007).

As atividades do Programa Bem Receber, que duraram até 2009, abrangeram capacitações e consultorias para a implantação de práticas de conservação ambiental, inclusão social e valorização da cultura local em empresas hoteleiras com base nas normas de sustentabilidade e sua atuação por meio de educação contínua, com treinamentos e uso de ferramentas didáticas (IH; MTUR, 2007). 
A ideia foi estimular a adesão às práticas sustentáveis, como: coleta seletiva de resíduos com destinação adequada e redução do lixo; racionalização do uso da água e de energia; utilização de produtos biodegradáveis e de baixo impacto poluidor; preservação ambiental; apoio à cultura e ao artesanato locais com valorização da mão de obra regional (TOMAZZONI; ZANETTE; LAIDENS, 2009). Tomazzoni, Zanette e Laidens (2009), em estudo sobre a participação de meios de hospedagem no Programa Bem Receber, concluíram que houve maior entendimento e assimilação do conceito de sustentabilidade e do desenvolvimento de habilidades para identificar os impactos do turismo, além de comprometimento com a comunidade local e fortalecimento na cooperação entre os participantes. Também houve melhorias na gestão, no atendimento e no monitoramento da satisfação dos clientes. Os participantes afirmaram que os maiores resultados, como a redução de custos e o aumento da taxa de ocupação, serão obtidos a médio e longo prazo e dependerão da persistência e dedicação dos gestores e colaboradores.

O Programa Turismo $100 \%$ foi lançado em 2009, mediante parceria do MTur com o Instituto Brasileiro da Qualidade e Produtividade (IBQP), com vistas à melhoria dos serviços turísticos por meio do incentivo e do apoio financeiro para certificação pelas normas brasileiras de gestão da sustentabilidade, gestão da segurança no turismo de aventura e de pessoas e de produtos turísticos. O programa propôs ações e eventos para sensibilização e divulgação junto aos integrantes do setor de turismo, bem como capacitação de auditores de sistemas de gestão nas áreas especificadas, dentro das estratégias de preparação para a Copa do Mundo de 2014 e para os Jogos Olímpicos e Paraolímpicos de 2016 (IBQP, 2012).

O programa consiste em gerar produtos turísticos sustentáveis, segurança nas atividades e segmentos do turismo, preservação dos recursos naturais e culturais, maior competitividade e qualidade na prestação de serviços com empresas e profissionais capacitados e certificados, além de turistas sensibilizados. Para isto, foram definidos os objetivos de: incentivar a acreditação de novos organismos de certificação na área do Turismo; capacitação de 300 auditores; avaliar a conformidade de 500 empresas e 32.500 profissionais do turismo para a certificação; realizar pesquisa de demanda por certificação de pessoas do turismo; identificar a necessidade de capacitação ou qualificação de pessoas nas ocupações do turismo; e avaliar os resultados alcançados (IBQP, 2012).

Em 2010 foi lançado o Programa Bem Receber Copa com vistas a atingir padrões internacionais de qualidade nos serviços turísticos no país. As ações do programa focaram na qualificação de 306 mil profissionais que atuam nos segmentos de: alimentação fora do lar; locadoras de automóveis; transporte aéreo regional; turismo de aventura; meios de hospedagem; agentes e operadoras de turismo; negócios e eventos (FGV, 2012). Em setembro de 2011 houve a suspensão temporária de execução de todos os convênios firmados com entidades privadas sem fins lucrativos, bem como os repasses de recursos, em função de um relatório do Tribunal de Contas da União (TCU) acerca dos riscos ao Erário Público e denúncias de esquemas de desvio de recursos do programa no Amapá.

O Quadro 1 apresenta uma síntese dos objetivos, da vigência e dos principais aspectos ou efeitos gerados por cada programa, que permite melhor compreendê-los.

Quadro 1: Síntese dos Programas Governamentais de Sustentabilidade do Turismo

\begin{tabular}{|c|c|c|c|}
\hline PROGRAMA & VIGÊNCIA & OBJETIVOS & PRINCIPAIS ASPECTOS/EFEITOS \\
\hline \multirow{2}{*}{$\begin{array}{l}\text { Certificação } \\
\text { em Turismo } \\
\text { Sustentável } \\
\text { (PCTS) }\end{array}$} & \multirow{2}{*}{$2002-2007$} & \multirow{2}{*}{$\begin{array}{l}\text { Melhorar a qualidade } \\
\text { e a competitividade do } \\
\text { turismo nacional, com } \\
\text { foco nas pequenas e } \\
\text { médias empresas. }\end{array}$} & $\begin{array}{l}\text { Positivos: elaboração de normas de } \\
\text { sustentabilidade; ações de capacitação } \\
\text { de gestores e trabalhadores; formação de } \\
\text { auditores em sustentabilidade; subsídios } \\
\text { quanto às consultorias e processos de } \\
\text { certificação em sustentabilidade. }\end{array}$ \\
\hline & & & $\begin{array}{l}\text { Negativos: ausência de ações de marketing } \\
\text { e comunicação para consolidar e estimular } \\
\text { o interesse, a adesão e a continuidade do } \\
\text { programa; falta de acompanhamento e } \\
\text { monitoramento do programa. }\end{array}$ \\
\hline
\end{tabular}




\begin{tabular}{|c|c|c|c|}
\hline \multirow[t]{2}{*}{ Bem Receber } & \multirow[t]{2}{*}{ 2007-2009 } & \multirow{2}{*}{$\begin{array}{l}\text { Contribuir para melhoria } \\
\text { da qualidade dos serviços } \\
\text { e competitividade do } \\
\text { setor turístico, com base } \\
\text { na gestão sustentável } \\
\text { e qualificação profis- } \\
\text { sional. }\end{array}$} & $\begin{array}{l}\text { Positivos: beneficiou meios de hospedagens } \\
\text { de } 30 \text { destinos selecionados com capacitações } \\
\text { e consultorias para implantação de práticas } \\
\text { de conservação ambiental, inclusão social e } \\
\text { valorização da cultura local; ocorrência das } \\
\text { primeiras certificações pela NBR } 15401 \text {. }\end{array}$ \\
\hline & & & $\begin{array}{l}\text { Negativos: curta duração do programa; } \\
\text { perda de credibilidade. }\end{array}$ \\
\hline $\begin{array}{l}\text { Turismo } \\
100 \%\end{array}$ & 2009-atual & $\begin{array}{l}\text { Melhoria dos serviços por } \\
\text { meio de certificação em } \\
\text { gestão (foco na Copa do } \\
\text { Mundo, Jogos Olímpicos } \\
\text { e Paraolímpicos). }\end{array}$ & $\begin{array}{l}\text { Positivos: acreditação de organismos } \\
\text { certificadores e capacitação de auditores de } \\
\text { sistemas de gestão em sustentabilidade. }\end{array}$ \\
\hline \multirow{2}{*}{$\begin{array}{l}\text { Bem Receber } \\
\text { Copa }\end{array}$} & \multirow{2}{*}{$\begin{array}{l}2010-2011 \\
\text { (suspenso) }\end{array}$} & \multirow{2}{*}{$\begin{array}{l}\text { Atingir padrões de } \\
\text { qualidade nos serviços } \\
\text { turísticos (foco na Copa } \\
\text { do Mundo). }\end{array}$} & $\begin{array}{l}\text { Positivo: cursos de qualificação profissional } \\
\text { para integrantes do setor nas cidades que } \\
\text { sediarão os jogos da Copa. }\end{array}$ \\
\hline & & & $\begin{array}{l}\text { Negativos: suspeitas de desvios de } \\
\text { recursos e irregularidades nos repasses } \\
\text { aos conveniados. }\end{array}$ \\
\hline
\end{tabular}

Fonte: Elaboração própria.

Todos os programas apresentados tiveram a mesma lógica de elaboração com fins de estimular e tornar o setor mais sustentável, em consonância com as metas dos Planos Nacionais do Turismo (PNT), por meio de qualificação e certificação em sustentabilidade. Geraram iniciativas de implantação de práticas socioambientais sustentáveis, desenvolvimento de normas e busca por certificação nas empresas do setor. Contudo, observa-se que cada programa teve a definição de objetivos diferentes que deveriam estar encadeados ou constituir no mínimo uma espinha dorsal para a política de turismo nacional. Porém, foram desenvolvidos de modo isolado e sem integração com outras iniciativas existentes. Também houve pouca atenção à participação dos integrantes do setor na formulação destes programas ou anteriores. Outro aspecto relevante é que os programas tiveram vigência curta, pois foram descontinuados quando começaram a maturar e gerar algum resultado positivo. Como agravante, tem-se o fato das recentes suspeitas de desvios e irregularidades nos repasses de recursos que recaem sobre o Programa Bem Receber Copa. Fatos que, somados, geraram problemas de credibilidade junto aos integrantes do setor turístico, especialmente naqueles que participaram e acreditaram nos objetivos de tais programas.

Um dos principais fatores dessa condição do turismo foi a pouca atenção dada à gestão do setor. $\mathrm{Na}$ verdade, o processo de planejamento e gestão do setor no Brasil passou por um crescimento quantitativo e imediatista da demanda interna, de empresas e de destinos turísticos ao longo das últimas décadas e com forte grau de centralização, quando deveria estar voltado para um desenvolvimento integrado e coerente com as necessidades e preocupações socioambientais, com descentralização na formulação e implantação. Em suma, um desenvolvimento de todos os seus setores de modo sustentável e com vistas à sua perenidade.

\section{CONSIDERAÇÕES FINAIS}

O crescimento e a consolidação do turismo como importante atividade socioeconômica trazem a responsabilidade de colaborar para o desenvolvimento sustentável, mediante a incorporação de práticas que reduzam os impactos ambientais negativos e incentivem aquelas que tragam melhorias ao planeta (OMT, 2004).

A sustentabilidade do turismo se baseia em: planejamento da atividade turística no médio e longo prazo e sua compatibilidade com outros setores; na gestão ambiental do espaço turístico 
impulsionado desde a gestão pública (municipal) até ao setor privado; e implica a conscientização e a formação de todos os afetados (residentes e turistas) (CAMPRUBÍ et al., 1998). Assim, existe a necessidade de se planejar um turismo com base na sustentabilidade e no respeito às culturas e às populações locais, na proteção à natureza e dos recursos naturais e na conscientização sobre os rumos de um crescimento qualitativo da humanidade. Um turismo que se torne "uma das melhores vias para alcançar o bem-estar econômico e social" (OMT, 2001, p. 32), mediante ordenamento, consciência e integração dos diversos stakeholders (governos, empresas, agentes turísticos, escolas, universidades, residentes e turistas) para uma readequação das condições de oferta e realização de um turismo mais sustentável.

Cabe aos governos exercerem papel central na fixação de critérios de desenvolvimento e coordenação dos agentes do setor, por meio de políticas públicas de turismo. O objetivo fundamental seria compatibilizar o princípio de liberdade de mercado com a preservação das vantagens estruturais que assegurem a continuidade da atividade em condições para se atingir um nível de competitividade entre empresas e regiões turísticas e propiciar o máximo de bem-estar e atendimento às necessidades dos consumidores do turismo (OMT, 2001).

O turismo não pode ficar alheio a esse processo que destaca a importância da questão socioambiental para o meio empresarial e pode valer-se de sistemas de gestão e certificação para se adequar e antecipar-se aos anseios dos clientes e às imposições legais, de modo proativo, crítico e responsável. Tais iniciativas podem ser estimuladas pelo poder público para definição de padrões mínimos de qualidade e desempenho socioambiental dos produtos e serviços turísticos e, assim, estimular a competição adequada, por meio da geração de informações claras e confiáveis para auxiliar nas opções de escolha da demanda turística. Para Bowman (2011, p. 271), "the national dialogue and development of sustainable tourism certification can play an important role in national branding as a tourism destination".

Em relação ao turismo no Brasil, à luz do exposto nas seções precedentes, pode-se intuir que o setor de turismo tem evoluído no país, porém não no mesmo ritmo e intensidade mundial. O Brasil possui enorme potencial de expansão da atividade do turismo e pode obter muitos benefícios com isto, mas não tem conseguido em verdade tornar uma realidade. Pior ainda, tem sido marcante o viés de alcance de crescimento econômico e pouca consideração tem ocorrido na prática para se atingir um nível de desenvolvimento sustentável do setor. Para Beni (2007, p. 142), "O turismo no Brasil ainda não atingiu índices de desenvolvimento mais expressivos devido à falta de uma visão sistêmica e holística e de pensamento estratégico".

Observa-se que a elaboração de normas de certificação em sustentabilidade para o turismo no país segue a concepção de Swarbrooke (2000), de tornar-se importante instrumento de atuação efetiva dos órgãos públicos para estabelecimento de padrões para um turismo sustentável. Contudo, emerge uma questão fundamental atinente a como os programas públicos são elaborados, pois estes são desenvolvidos e implementados de modo isolado, em um pensamento de curto prazo e focados quase que na operacionalização dos objetivos do PNT vigente, e não como instrumentos estratégicos de gestão do setor no longo prazo.

O poder público necessita perceber que "a crescente complexidade do fenômeno turístico aconselha uma maior descentralização na tomada de decisões que afetam o setor" (OMT, 2001, p. 163), de modo que a realização do turismo no país e a sua gestão deveriam ir ao encontro das necessidades da população local, garantir a proteção ambiental, satisfazer a demanda turística atual e manter a atração dos destinos turísticos no mesmo nível que sua qualidade ambiental. Assim, é requerido que os governos em seus diversos níveis (nacional, regional e local), as empresas do setor e as comunidades locais desenvolvam políticas conjuntas para fomento socioeconômico.

Políticas que não sejam apenas restritas ao âmbito dos discursos vazios e das intenções não realísticas, mas sim em ações efetivas, para que o país viva um desenvolvimento turístico baseado no planejamento integrado, participativo e estratégico, com aproveitamento racional e responsável de seus recursos ambientais e histórico-culturais (SILVEIRA, 2005), que decidam as prioridades do turismo quanto a um desenvolvimento sustentável, local e mundial, mais condizente com o papel na prosperidade e na consciência quanto à conservação e ao manejo dos recursos naturais. Quiçá, que incluam aspectos de comercialização, mercadologia, qualidade, produtividade e competitividade dos bens e dos serviços turísticos em um pensar planejado e estratégico (BENI, 2000). 
Os planos e os programas governamentais nacionais aqui apresentados tiveram como uma de suas finalidades o estímulo ao turismo sustentável, porém foram desenvolvidos sem integração com outras iniciativas, sofrem com a descontinuidade e com a consequente falta de credibilidade junto aos integrantes do setor. Assim, não conseguem ter uma perenidade e obter consistência ao longo do tempo e credibilidade perante aos diversos interessados na cadeia produtiva do turismo até chegar aos turistas. Espera-se que isto não venha a acontecer com o Programa Turismo 100\% ainda vigente.

O país precisa ter clara uma política pública de Estado para o turismo que possa sobrepor-se aos interesses dos detentores do poder e seja construída por meio de participação coletiva e tenha continuidade ao longo do tempo. Conforme Sansolo e Cruz (2003, p. 3), "Uma cultura de valorização do turismo não é algo que se constrói da noite para o dia ou por meio de atos administrativos ou de diplomas legais. Isto somente pode ser construído social e historicamente". Para finalizar, é fundamental que se busque uma resposta apropriada para os seguintes questionamentos: qual o modelo de desenvolvimento e qual o tipo de turismo que se quer adotar no Brasil?

\section{REFERÊNCIAS}

ASSOCIAÇÃO BRASILEIRA DE NORMAS TÉCNICAS (ABNT). Comitê Brasileiro de Normalização em Turismo - CB 54. Disponível em: <http://www.abntcatalogo.com.br/mtur/>. Acesso em: 30 abr. 2012.

BARDDAL, R.; ALBERTON, A.; CAMPOS, L. M. de S. As dimensões e métodos de mensuração da sustentabilidade e o turismo: uma discussão teórica. Revista de Gestão Social e Ambiental, v. 4, n. 2, p.138-155, maio/ago. 2010.

BENI, M. C. Análise estrutural do turismo. 3. ed. rev. e ampl. São Paulo: Ed. SENAC, São Paulo, 2000.

Planejamento estratégico e gestão local/regional do turismo. In: SEABRA, G. (Org.). Turismo de base local: identidade cultural e desenvolvimento regional. João Pessoa: Universitária UFPB, 125150,2007

BOULLÓN, R. C. Las actividades turísticas y recreacionales: el hombre como protagonista. 3. ed. reimpr. México: Trillas, 1995.

BOWMAN, K. S. Sustainable tourism certification and state capacity: keep it local, simple, and fuzzy. International Journal of Culture, Tourism and Hospitality Research, v. 5, n. 3, p. 269-281, 2011.

BRASIL. Decreto n० 7.381, de 2 de dezembro de 2010. Regulamenta a Lei no 11.771 , de 17 de setembro de 2008, que dispõe sobre a Política Nacional de Turismo, define as atribuições do Governo Federal no planejamento, desenvolvimento e estímulo ao setor turístico, e dá outras providências. Diário Oficial [da] República Federativa do Brasil. Brasília, DF, 18 set. 2008. Disponível em: <http://www.planalto.gov.br/ ccivil_03/_Ato2007-2010/2010/Decreto/D7381.htm>. Acesso em: 30 abr. 2012.

CAMPRUBÍ, R. B.; MARCO, L. P.; CABADo, J. S.; RIERA, F. V. Turismo y médio ambiente. Madrid: Centro de Estudios Ramón Areces, 1998.

DENCKER, A. de F. M. Métodos e técnicas de pesquisa em turismo. São Paulo: Futura, 1998.

DIAS, R. Planejamento do turismo: política e desenvolvimento do turismo no Brasil. São Paulo: Atlas, 2003.

FUNDAÇÃO GETÚLIO VARGAS (FGV). Disponível em: <http://www5.fgv.br/fgvonline/mtur/programa. asp>. Acesso em: 30 abr. 2012.

Fundação Getúlio Vargas (FGV); Ministério do Turismo (MTUR). Pesquisa anual de conjuntura econômica do turismo / EBAPE/ Núcleo de Turismo, Ministério do Turismo. 7. ed. Rio de Janeiro: Edit. Fundação Getúlio Vargas, 2011.

GALDINO, L. C. F.; COSTA, M. L. da. Análise das principais políticas públicas de turismo no Brasil, da década de 1990 à atualidade. Revista Acadêmica Observatório de Inovação do Turismo, v. 6, n.4, 24p., set. 2011.

INSTITUTO BRASILEIRO DA QUALIDADE E PRODUTIVIDADE (IBQP). Disponível em: < http://www. ibqp.org.br/turismo/conheca-o-turismo.php>. Acesso em: 04 jan. 2012. 
iNSTITUTO BRASILEIRO DE GEOGRAFIA E ESTATÍSTICA (IBGE). Pesquisa Anual de Serviços - 2008. Disponível em: <http://www.ibge.gov.br/home/estatistica/economia/comercioeservico/pas/pas2008/ defaulttabpdf.shtm>. Acesso em: 15 maio 2012.

INSTITUTO BRASILEIRO DE TURISMO (EMBRATUR). Disponível em: < http://www.turismo.gov.br/ turismo/o_ministerio/embratur/>. Acesso em: 26 dez. 2011.

INSTITUTO DE HOSPITALIDADE (IH); MINISTÉRIO DO TURISMO (MTUR). Hospitalidade: guia para profissionais operacionais. Salvador, 2007.

MINISTÉRIO DA INDÚSTRIA, DO COMÉRCIO E DO TURISMO (MDIC). Disponível em: <http://www. mdic.gov.br//sitio/interna/interna.php?area=1\&menu=1662>. Acesso em: 30 abr. 2012.

MINISTÉRIO DO TURISMO (MTUR). Plano Nacional do Turismo - Diretrizes, Metas e Programas - 20032007. Brasília, 29 abr. 2003.

2007.

Plano Nacional do Turismo - PNT 2007/2010 - uma Viagem de Inclusão. Brasília, jun.

Anuário Estatístico de Turismo - 2011. v. 38, Ano base 2010. Secretaria Nacional de Políticas de Turismo. Brasília, 2011.

NOIA, A. C.; VIEIRA JÚNIOR, A.; KUSHANO, E. S. Avaliação do Plano Nacional de Turismo: Gestão do Governo Lula, entre os anos de 2003 a 2007. CULTUR - Revista de Cultura e Turismo, ed. Especial. ano 1, n.1, p. 23-38, out. 2007.

ORGANIZAÇÃO MUNDIAL DO TURISMO (OMT). Introdução ao turismo. Amparo Sancho (dir. red.). São Paulo: Roca, 2001.

Iniciativas voluntárias para o turismo sustentável: inventário mundial e análise comparativa de 104 selos ecológicos, prêmios e iniciativas de autocomprometimento. São Paulo: Roca, 2004.

PROCHNOW, W. E.; VASCONCELOS, E. C. de. O estado-da-arte das ações para certificação em ecoturismo. Caderno Virtual de Turismo, v. 8, n. 3, p.29-40, 2008.

PROGRAMA DAS NAÇÕES UNIDAS PARA O MEIO AMBIENTE (PNUMA).

ORGANIZAÇÃO MUNDIAL DO TURISMO (OMT). Por un turismo más sostenible: guia para responsables políticos. Autores, 2005.

SANSOLO, D. G.; CRUZ, R. de C. A. de. Plano Nacional do Turismo: uma análise crítica. Caderno Virtual de Turismo, v. 3, n. 4, p.1-6, 2003.

SILVEIRA, M. A. T. de. Turismo y sustentabilidad - entre el discurso y la acción. Estudios y Perspectivas em Turismo. v. 14, n. 3, 222-242, jul. 2005.

SOUZA, M. J. B. de; FERREIRA, E. Planos Nacionais de Turismo, Desenvolvimento Local e Sustentabilidade. In: Encontro Nacional da ANPAD, 35, 2011, Rio de Janeiro. Anais... Rio de Janeiro: ANPAD, 2011. 1 CDROM.

SWARBROOKE, J. Turismo sustentável: meio ambiente e economia. v. 2, 3a ed. São Paulo: Aleph. 2000.

TOMAZZONI, E. L.; ZANETTE, F. C.; LAIDENS, M. C. Gestão em hotelaria e sustentabilidade ambiental: análise da experiência do Programa Bem Receber na região das hortênsias (Serra Gaúcha). Revista Acadêmica Observatório de Inovação do Turismo, v. 4, n.3, 14p., set. 2009.

WORLD TRAVEL \& TOURISM COUNCIL (WTTC). Travel \& Tourism Economic Impact 2011. Disponível em: <http://www.wttc.org/research/economic-impact-research/country-reports/b/brazil/>. Acesso em: 05 Jan. 2012. 